\title{
QUANTIFICATION OF DEEP-TIME ORBITAL FORCING BY AVERAGE SPEGTRAL MISFIT
}

\author{
STEPHEN R. MEYERS*' ${ }^{\dagger}$ and BRADLEY B. SAGEMAN**
}

\begin{abstract}
Quantification of Milankovitch orbital cyclicity within ancient strata has become a principal tool for refinement of the geologic time scale. However, accurate characterization of the orbital signal in deep time paleoclimate records is commonly challenged by inadequate radiometric time constraints for calibration of the spatial rhythms to temporal periods. This problem can potentially introduce large errors into derivative orbital timescales. In this study we develop a new method for the identification and calibration of orbital cyclicity in cyclostratigraphic records. The method (average spectral misfit, or ASM) yields an objective estimate of the optimal sedimentation rate for a stratigraphic interval that preserves a record of orbital forcing. The technique also provides a formal statistical test for rejecting the null hypothesis (no orbital signal). Application of the method to assess orbital cyclicity in the upper Bridge Greek Limestone Member (Turonian) of the Western Interior Basin highlights the utility of this new cyclostratigraphic tool, and provides a means to independently evaluate conflicting interpretations of the lithologic cycles. Importantly, ASM offers a new consistent standard by which orbital timescales may be compared. Hence, the quality of an orbital timescale can be formally qualified by reporting its average spectral misfit and null hypothesis significance level. This technique will permit improvement of Mesozoic/Cenozoic orbital timescales and extension of orbital time scale development into the Paleozoic, as the method is not dependent upon wellconstrained radiometric age data.
\end{abstract}

\section{INTRODUCTION}

As originally observed by Gilbert (1895), many rhythmically bedded hemipelagic deposits appear to reflect environmental oscillations on a timescale consistent with the astronomical cycles. Subsequent studies have recognized that lithologic rhythms preserved in deep-sea settings, carbonate platforms, and even lacustrine environments may also reflect orbitally forced/paced variations in climate (Schwarzacher, 1947; Fischer, 1980; Fischer and others, 1985; Herbert and Fischer, 1986; Olsen, 1986; Goldhammer and others, 1990; and many others). To move from these general observations to the empirical identification of specific orbital periods, construction of an orbital time scale, and interpretation of how the orbital-insolation signal influenced climate and sedimentation, however, requires a series of specific measurements, as well as application of certain uniformitarian assumptions.

Generally, confirmation of orbital influence requires reduction of the lithologic signal to a finely sampled data series (for example, geochemical, color or bed thickness), application of appropriate Fourier techniques to identify significant spatial frequencies, and calibration of the observed spatial frequencies to temporal periods. Although this approach has become commonplace, there are many aspects of sampling and data analysis that can result in the introduction of error. Among these aspects, temporal calibration of spatial rhythms in the absence of adequate radiometric time control requires important assumptions about sedimentation rate, which can result in substantial errors in the orbital interpretation and derivative orbital timescales. Variability in sedimentation rate within a given stratigraphic interval (for example, Meyers and others, 2001), stratigraphic changes in the dominance of one

*University of North Carolina at Chapel Hill, Department of Geological Sciences, Chapel Hill, North Carolina 27599, USA; Email: smeyers@email.unc.edu

**Department of Geological Sciences, Northwestern University, Evanston, Illinois 60208, USA

${ }^{\dagger}$ Corresponding author 
orbital cycle over others (de Menocal, 1995; Sageman and others, 1997; Hinnov and others, 2000) and geographic changes in orbital cycle expression (Berger and Pestiaux, 1984; Park and Ogelsby, 1991) introduce additional complications that tend to be ignored in many cyclostratigraphic studies.

In this paper we develop a new statistical method to test for the presence of Milankovitch orbital cyclicity in paleoclimate records that lack adequate radiometric time control. The method, termed average spectral misfit (ASM), explicitly evaluates timescale uncertainty and takes into consideration fundamental limitations imposed by the stratigraphic sampling procedures. We demonstrate the utility of this method using two synthetic models, and as a case study, we apply the method to resolve an ongoing controversy about the interpretation of orbital cyclicity within the proposed Cenomanian/Turonian (C/T) stratotype of Colorado (USA; Kennedy and Cobban, 1991; Kennedy and others, 2000). Given the central role of astronomical tuning in construction of the geologic time scale (Gradstein and others, 2004), and the plethora of (sometimes conflicting) cyclostratigraphic interpretations, this method provides an important new tool for evaluation and comparison of orbital timescales. Ultimately, this method will allow more accurate reconstruction of geologic time.

\section{BACKGROUND}

A variety of techniques have been proposed to test for an orbital signal in stratigraphic records lacking sufficient radiometric time control (for example, Schawarzacher, 1947; Park and Herbert, 1987; Kominz and Bond, 1990; Herbert, 1992; D'Argenio and others, 1997; Hinnov and Park, 1998). The most commonly utilized method employs frequency ratios (henceforth, the "ratio method") to interpret power spectrum peaks, such as the $\sim 5: 2: 1$ relationship between short eccentricity $(\sim 100 \mathrm{kyr})$, the dominant obliquity component $(\sim 40 \mathrm{kyr})$, and precession $(\sim 20 \mathrm{kyr})$. Although simple application of the ratio method may be successful under some circumstances, corruption of the orbital signal by sedimentation rate changes and other sources of signal distortion (see below) can severely complicate its use. Furthermore, as commonly employed, this method does not provide an explicit statistical test for rejection of the null hypothesis (no orbital forcing). What degree of deviation of the observed ratios from predicted orbital values is permissible before the orbital hypothesis must be rejected?

Signal distortion associated with propagation of the Milankovitch orbitalinsolation signal through the climate system and depositional environment, and errors introduced by diagenesis, proxy fidelity, and sampling protocol can present important challenges to accurate identification of the orbital components. For example, the impact of secular sedimentation rate changes and hiatus on the preserved orbital record is well documented (Park and Herbert, 1987; Weedon, 1989; Meyers and others, 2001; Meyers and Sageman, 2004). Differential accumulation during cycle development can further distort the orbital signal by generating artificial harmonics in the spectral results (Schiffelbein and Dorman, 1986; Meyers and others, 2001). The first harmonic of a $20 \mathrm{kyr}$ precession component is $10 \mathrm{kyr}$, creating a 2:1 ratio reminiscent of obliquity $(\sim 40 \mathrm{kyr})$ and precession $(\sim 20 \mathrm{kyr})$. Alternatively, a true semi-precession signal may be preserved in some low latitude settings (for example, Park and others, 1993). As another example, Ripepe and Fischer (1991) illustrate how depositional system response can transfer power from carrier frequency (precession) to modulator frequency (eccentricity). This transfer of power is attributable to non-linear processes (for example, non-linear response of biogenic flux to insolation changes), and could also theoretically occur for obliquity ( $\sim 40 \mathrm{kyr})$ and its significant modulation periods that occur around $\sim 200 \mathrm{kyr}$ (Hinnov, 2000). Given the sources of uncertainty inherent in the stratigraphic record (for example, sedimentation rate 
changes), and the resolution limitations of most spectral techniques, this $\sim 4: 1$ relationship could quite easily be confused for a 5:1 eccentricity: precession signal.

As a final example, error can be introduced by inadequate sampling of the orbital components, which will generate aliased signals (for example, a sampling frequency of $50 \mathrm{kyr}$ will alias an obliquity signal into a frequency band around $\sim 200 \mathrm{kyr}$ ). Even if high-resolution data series are employed for quantification of the bedding cyclicity, transient drops in sedimentation rate may still result in aliasing in portions of the data record. Although these examples are relatively simple, they illustrate some of the main complications and pitfalls inherent in quantification of the orbital signal. Clearly a more sophisticated and rigorous assessment of the fit of spectral results to a Milankovitch model is needed, especially given the resolution limitations of most prePleistocene radiometric time scales.

AVERAGE SPECTRAL MISFIT

Although precise orbital-insolation time series cannot be determined prior to $\sim 50$ Ma (Laskar and others, 2004), theoretical estimates of the eccentricity, obliquity and precession frequencies are expected to be accurate over the past $500 \mathrm{Ma}$ (Berger and others, 1992). A number of cyclostratigraphic studies support these theoretical calculations (for example, Park and Herbert, 1987; D'Argenio and others, 1997; Weedon and Jenkyns, 1999; Meyers and others, 2001). The new metric developed in this study provides a quantitative evaluation of how well different temporal calibrations of a measured stratigraphic time series fit the predicted orbital components. Thus, the method can be considered a more sophisticated application of the commonly employed ratio method.

We propose that a suitable metric for identification of the astronomical signal should have several important characteristics. First, it should employ a robust spectral technique for quantification of significant spatial bedding periods. Furthermore, the method should not be severely compromised by non-linearities introduced by the orbital-insolation transfer functions (for example, generation of harmonics, transfer of power from carrier frequency to modulator frequency, changes in sedimentation rate, et cetera), and should account for inherent resolution limits associated with the sampling protocol. Finally, the method should provide a means to test the statistical significance of the results, thus permitting rejection of the null hypothesis of no orbital forcing.

A detailed explanation of the misfit parameter is outlined in the Appendix, but we provide a brief introduction here. We define the average spectral misfit (ASM) as,

$$
A S M=\frac{1}{n} \sum_{k=1}^{n} \alpha_{k} \quad \text { where } \alpha_{k}= \begin{cases}0 & \text { if }\left|\left(f^{*} s\right)-f_{\text {pred }}\right| \leq 0.5^{*} \Delta f_{R}^{*} s \\ \left|\left(f^{*} s\right)-f_{\text {pred }}\right| & \text { if }\left|\left(f^{*} s\right)-f_{\text {pred }}\right|>0.5^{*} \Delta f_{R}^{*} s\end{cases}
$$

$n=$ number of orbital periods in analysis

$k=$ summation index

$f=$ spatial frequency peak location (cycles/meter)

$s=$ sedimentation rate $(\mathrm{m} / \mathrm{kyr})$

$f^{*}=$ calibrated temporal frequency peak location (cycles $/$ kyr $)$

$f_{\text {pred }}=$ predicted orbital frequency (cycles $/$ kyr)

$\Delta f_{R}=$ spatial frequency resolution bandwidth (cycles/meter), or minimum resolution bandwidth

$\Delta f_{R}{ }^{*} s=$ calibrated temporal frequency resolution bandwidth (cycles/kyr)

Figure 1 illustrates how changes in the temporal calibration (" $s$ " in eq. 1) impact the observed spectrum. As depicted in this figure, increases in sedimentation rate serve 

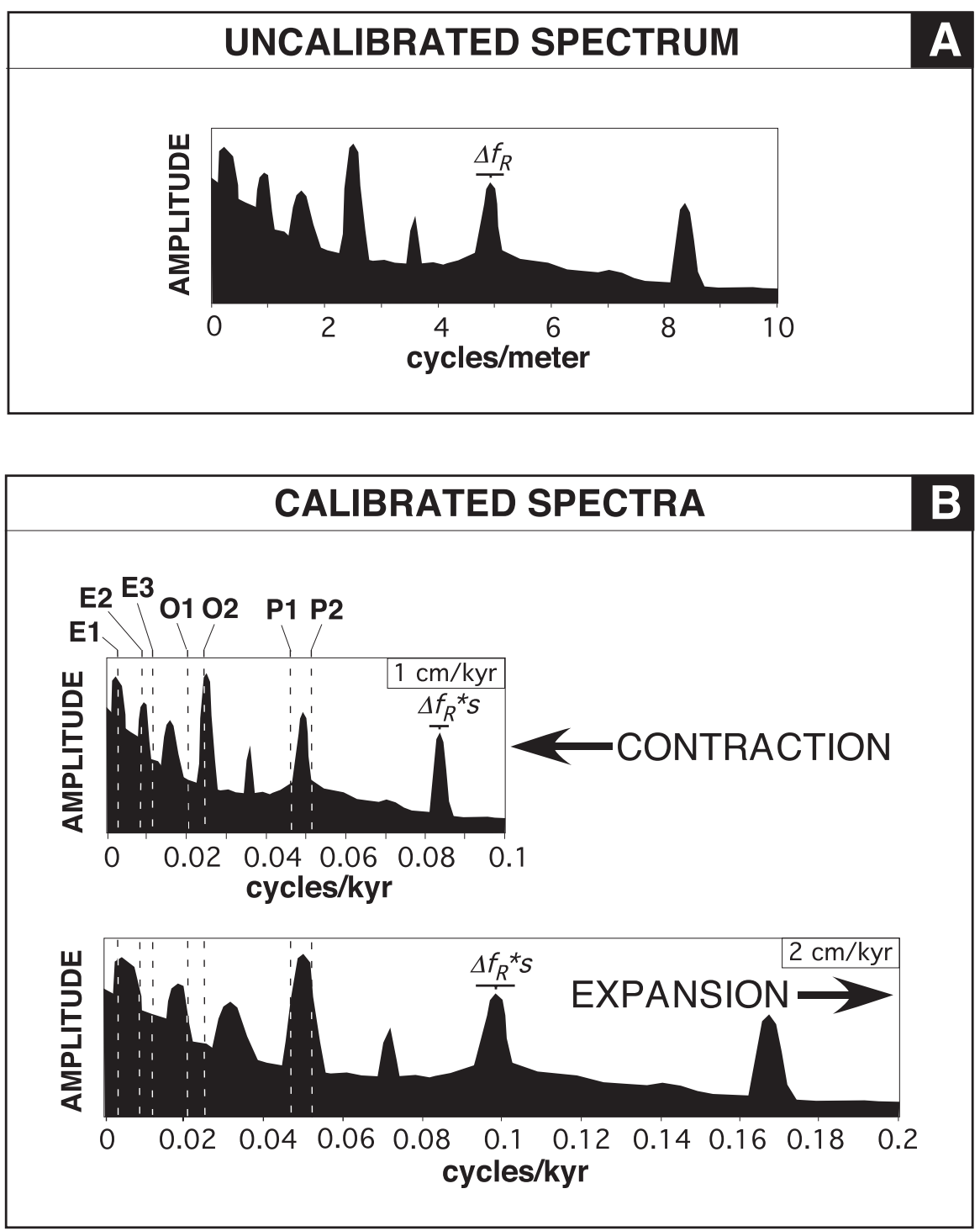

Fig. 1. (A) Hypothetical uncalibrated spectrum, in cycles/meter. (B) The spectrum from A, calibrated with sedimentation rates of $1 \mathrm{~cm} / \mathrm{kyr}$ and $2 \mathrm{~cm} / \mathrm{kyr}$. Expected locations of the mid-Cretaceous eccentricity $(\mathrm{E} 1=404 \mathrm{kyr}, \mathrm{E} 2=124 \mathrm{kvr}, \mathrm{E} 3=95 \mathrm{kvr})$, obliquity $(\mathrm{O} 1=50 \mathrm{kyr}, \mathrm{O} 2=39 \mathrm{kyr})$ and precession $(\mathrm{P} 1=22 \mathrm{kyr}$, $\mathrm{P} 2=19 \mathrm{kyr})$ periods are displayed as dashed lines. $\Delta f_{R}$ identifies the spatial frequency resolution bandwidth (Appendix), and $s$ represents the sedimentation rate. Temporal calibration serves to expand or contract the abscissa of the spectrum, and also changes the frequency resolution $\left(\Delta f_{R}{ }^{*}\right)$.

to expand the abscissa, as well as the temporal frequency resolution bandwidth $\left(\Delta f_{R}{ }^{*} s\right)$. The $\alpha_{\kappa}$ parameter in eq. 1 measures the distance between the location of the predicted orbital component and the closest significant peak in the spectrum $\left(f^{*} s\right)$, given a particular sedimentation rate, while accounting for inherent resolution limitations $\left(\Delta f_{R}{ }^{*}\right.$ and the Nyquist frequency; see Appendix). After summing the $\alpha_{\mathrm{k}}$ for each detectable orbital component (that is, the precession, obliquity and eccentricity terms), the subsequent value is divided by the number of fitted orbital periods to 


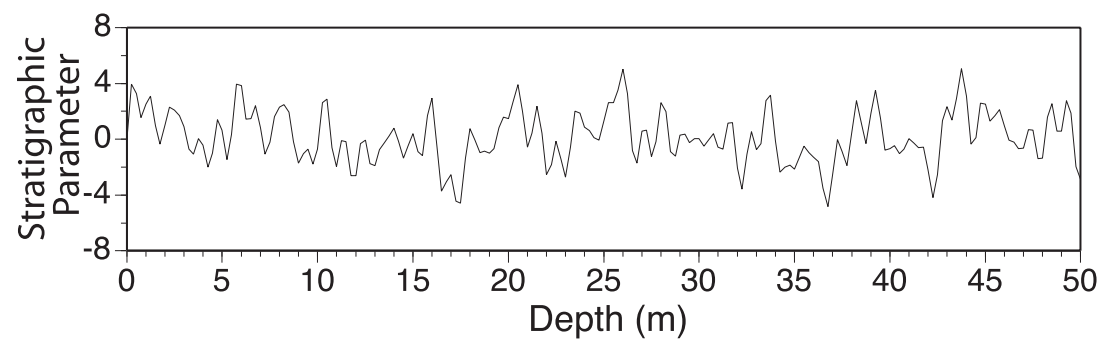

Fig. 2. A 50-meter long stratigraphic model, generated to contain the seven predicted mid-Cretaceous orbital components (E1, E2, E3, O1, O2, P1, P2) of Berger and others (1992), with a sedimentation rate of 5 $\mathrm{cm} / \mathrm{kyr}$, and a sampling interval of $25 \mathrm{~cm}$. The amplitude of each orbital period is unity.

determine an average spectral misfit. This metric has a number of advantageous qualities:

(1) The method accounts for the variable sensitivity of the spectrum given the range of plausible temporal calibrations. High sedimentation rates inherently increase the temporal frequency resolution bandwidth, while low sedimentation rates decrease this parameter. The incorporation of a minimum resolution bandwidth term $\left(0.5^{*} \Delta f_{R}{ }^{*} s\right)$ accounts for this frequency resolution limitation, and thus guards against artificial ASM inflation or deflation.

(2) For a given temporal calibration, some of the orbital frequencies can lie above the Nyquist frequency (the largest frequency in the spectrum) or below the Rayleigh frequency (the lowest positive frequency in the spectrum). Since these orbital frequencies cannot be robustly detected they are excluded from the misfit analysis. By calculating the average spectral misfit, it is possible to impartially compare calibrations that resolve a different number of orbital periods.

(3) Significance levels for rejection of the null hypothesis (no orbital signal) are easily determined by performing Monte Carlo simulations $(\geq 5000)$ of spectra with randomly distributed frequencies. These simulated spectra are then employed to generate unique ASM probability distributions for each sedimentation rate. Specifically, the null hypothesis $\left(\mathrm{H}_{\mathrm{O}}\right)$ significance levels indicate how frequently a particular ASM value should occur by chance, given a spectrum with randomly distributed frequencies.

(4) The ASM metric is used in conjunction with the Multi-taper method (MTM) of Thomson (1982), which permits identification of statistically significant harmonic components within the stratigraphic data series. Use of the MTM harmonic F-test is favorable because these spectral estimates have a minimum resolution bandwidth (Harris, 1978) that is approximately equivalent to the Rayleigh resolution (Thomson, 1990; see Appendix).

(5) Finally, the units of the ASM metric are physically interpretable (cycles/kyr), and represent a consistent standard by which orbital timescales derived in different studies may be compared. Hence, the quality of an orbital timescale can be formally qualified by reporting the associated average spectral misfit and its null hypothesis significance level.

AN ILLUSTRATION OF THE AVERAGE SPECTRAL MISFIT METHOD

Figure 2 displays a 1 Ma long stratigraphic model $(50 \mathrm{~m}$ accumulated at 5 $\mathrm{cm} / \mathrm{kyr}$ ), generated to contain the seven predicted mid-Cretaceous orbital periods of Berger and others (1992). These include eccentricity $(\mathrm{E} 1=404.18 \mathrm{kyr}, \mathrm{E} 2=123.82 \mathrm{kyr}$, 
$\mathrm{E} 3=94.78 \mathrm{kyr})$, obliquity $(\mathrm{O} 1=50.44 \mathrm{kyr}, \mathrm{O} 2=38.94 \mathrm{kyr})$, and precession $(\mathrm{P} 1=22.34$ $\mathrm{kyr}, \mathrm{P} 2=18.54 \mathrm{kyr})$. Given the modeled sedimentation rate, these temporal periods correspond to spatial frequencies of $\sim 0.05,0.16,0.21,0.40,0.51,0.9$, and 1.08 cycles/meter, respectively. This synthetic record has a sampling rate of $25 \mathrm{~cm}(5 \mathrm{kyr})$, which permits resolution of all input orbital periods.

The procedures utilized to determine average spectral misfit and its statistical significance are illustrated with this model. Multi-taper method spectral analysis (Thomson, 1982) of the model data series identifies the seven orbital components, all of which have a harmonic F-test significance level (FSL) exceeding 99.9 percent (fig. $3 \mathrm{~A})$. These seven significant frequencies are utilized to calculate the average spectral misfit across a range of plausible sedimentation rates (fig. 3B). Also plotted in this figure are the number of orbital terms available for calculation of spectral misfit (fig. 3C). For sedimentation rates above $\sim 12.5 \mathrm{~cm} / \mathrm{kyr}$ the first eccentricity component $(\mathrm{E} 1=404.18 \mathrm{kyr})$ is not evaluated as it falls below the first positive frequency in the spectrum (the Rayleigh frequency). Similarly, at sedimentation rates below $2.7 \mathrm{~cm} / \mathrm{kyr}$ the second precession component $(\mathrm{P} 2=18.54 \mathrm{kyr})$ is not evaluated due to limitations imposed by the Nyquist resolution (see Appendix).

To determine the statistical significance of the ASM results in figure 3B, Monte Carlo simulations are conducted by generating thousands of randomly organized spectra with the same resolution limitations as the measured spectrum (that is, identical Rayleigh resolution and Nyquist frequency). At every sedimentation rate of interest, the average spectral misfit for each simulation is determined, from which probability distribution functions are constructed. The resultant probability distribution functions are utilized to estimate significance levels for rejection of the null hypothesis (fig. 3D).

Formally, the null hypothesis being tested is that the measured ASM value is derived from a spectrum with randomly distributed frequencies (drawn from a uniform distribution). The statistical significance test seeks to determine how well random spectra fit the predicted orbital components given the resolution limits of the measured spectrum. The $\mathrm{H}_{\mathrm{O}}$-significance levels determined in this fashion indicate how frequently we should expect a particular ASM value given a spectrum that is randomly organized. A 0.1 percent significance level indicates that 99.9 percent of the random spectra are characterized by a larger ASM, thus the likelihood that the null hypothesis will be erroneously rejected is only 0.1 percent. An alternate, but equivalent interpretation is that there is only a 0.1 percent probability that such an ASM value could be derived by chance.

A critical parameter in the calculation of $\mathrm{H}_{\mathrm{O}}$-significance levels is the number of frequencies utilized in the Monte Carlo spectra simulations. One approach is to use the number of significant frequencies identified in the measured spectrum (seven, fig. $3 \mathrm{~A}$ ), as this quantity was employed in calculating ASM for the cyclostratigraphic data series (fig. 3B). An alternative approach is to utilize MTM harmonic F-test significance levels to estimate the appropriate number of frequencies. As an example, given a MTM spectrum that can resolve 100 discrete positive frequencies, and a 90 percent harmonic FSL threshold for identification of significant frequencies, we should expect 10 false positives in this portion of the spectrum. Thus, ten frequencies can be utilized for $\mathrm{H}_{\mathrm{O}}$-significance level calculation. Although both of the criteria outlined above have validity, in practice the approach that results in a greater number of frequencies will generate the most conservative $\mathrm{H}_{\mathrm{O}}$-significance levels.

The analysis presented in figure 3 utilizes 10 frequencies (the $90 \%$ harmonic FSL), and identifies a perfect fit at a sedimentation rate of $5 \mathrm{~cm} / \mathrm{kyr}(\mathrm{ASM}=0$ cycles/kyr, $0.001 \% \mathrm{H}_{\mathrm{O}}$-significance level; figs. 3B and 3D). All other sedimentation rates yield ASM values greater than zero, and more importantly, they are characterized 


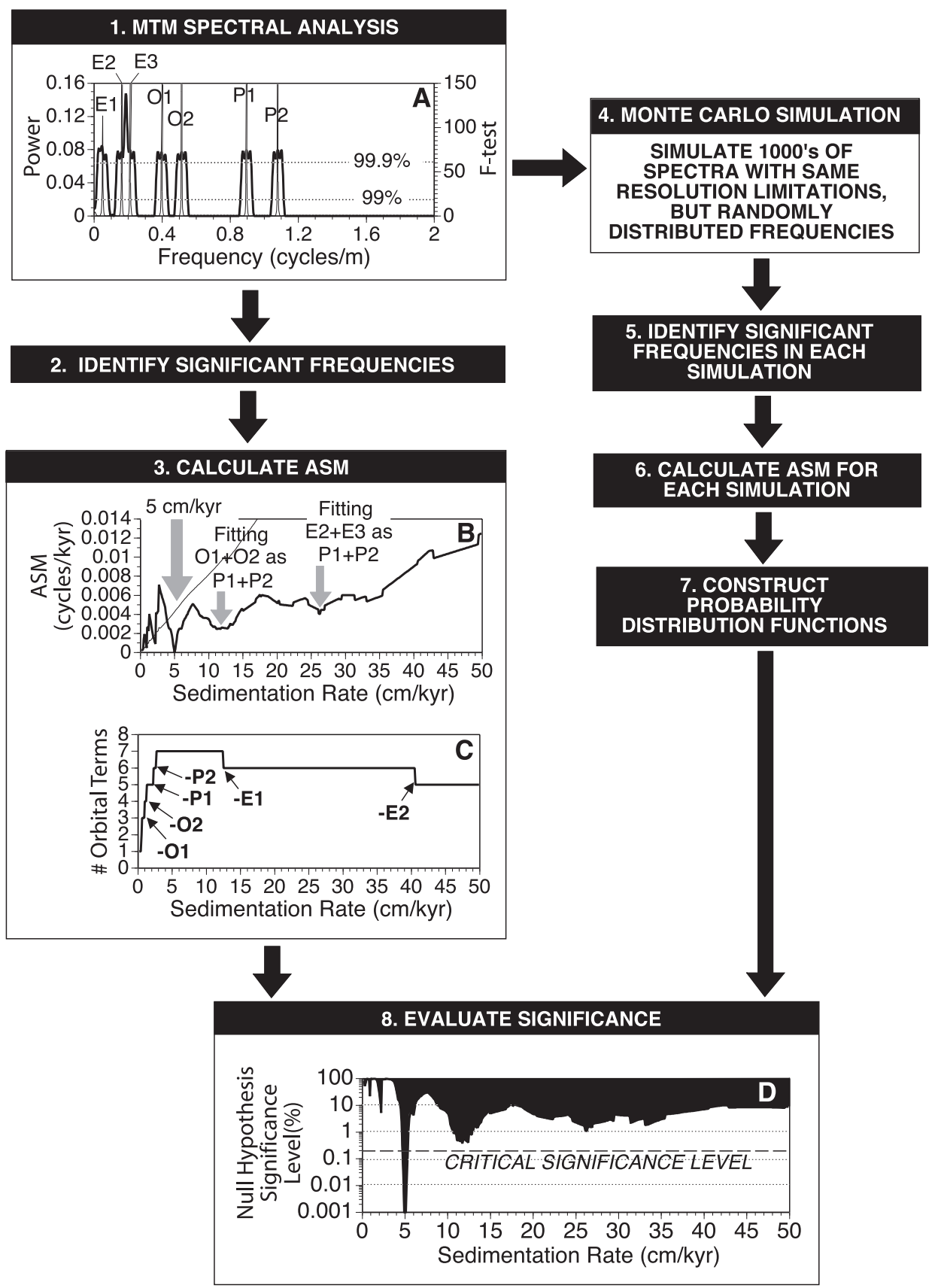

Fig. 3. Flow chart for analysis of the stratigraphic model shown in figure 2. (Numbers 1-8 refer to steps in the methodology.) (A) Three-taper $2 \pi$ MTM power spectrum (thick bold line) and F-test results (thin line) for the model in figure 2. Dotted lines indicate the $99 \%$ and $99.9 \%$ F-test significance levels. (B) Average spectral misfit results for the model (thick bold line), and the median ASM for each $\mathrm{H}_{\mathrm{O}}$-probability distribution (thin line). Beyond $17.1 \mathrm{~cm} / \mathrm{kyr}$, the median ASM exceeds $0.014 \mathrm{cycles} / \mathrm{kyr}$. (C) The number of Milankovitch terms that were available for calculation of ASM. (D) $\mathrm{H}_{\mathrm{O}}$-significance levels for the model, calculated using 10 frequencies per spectrum and 100,000 simulated spectra. The dashed line indicates the critical significance level. See text for further discussion. 
by null hypothesis significance levels that are generally several orders of magnitude larger. In this regard, it is important to note that 498 individual sedimentation rates are investigated in the analysis, approximately five of which should reach the 1 percent $\mathrm{H}_{\mathrm{O}}$-significance level purely by chance, and approximately 1 of which should reach the 0.2 percent $\mathrm{H}_{\mathrm{O}}$-significance level. We recommend this second significance level (the inverse of the number of sedimentation rates investigated) as the critical level necessary to reject the null hypothesis. As figure 3D displays, this critical level is surpassed at a sedimentation rate of $5 \mathrm{~cm} / \mathrm{kyr}$. Thus, the analysis indicates an optimal sedimentation rate of $5 \mathrm{~cm} / \mathrm{kyr}$, and we can reject the null hypothesis that the observed spectrum was derived from a random signal with a high degree of confidence.

In addition to the global minimum at $5 \mathrm{~cm} / \mathrm{kyr}$, the $\mathrm{H}_{\mathrm{O}}$-significance levels plotted in figure $3 \mathrm{D}$ also indicate a local minimum at $11.7 \mathrm{~cm} / \mathrm{kyr}\left(\mathrm{ASM}=2.58 \times 10^{-3} \mathrm{cycles} / \mathrm{kyr}\right.$, $0.77 \% \mathrm{H}_{\mathrm{O}}$-significance level). At this sedimentation rate, the obliquity terms yield a relatively good fit to the expected precession periods (with estimated values of 21.58 kyr and $16.63 \mathrm{kyr}$ ), and the short eccentricity terms yield a relatively good fit to the expected obliquity periods (with estimated values of $52.76 \mathrm{kyr}$ and $40.70 \mathrm{kyr}$ ). Another local minimum with a $\mathrm{H}_{\mathrm{O}}$-significance level slightly above 1 percent occurs at a sedimentation rate of $26.3 \mathrm{~cm} / \mathrm{kyr}$, where the short eccentricity terms are fit as precession. This example illustrates why studies that employ the traditional ratio method can derive erroneous interpretations of a preserved orbital record, especially if the full range of plausible sedimentation rates are not considered.

Finally, it is worthwhile to note that most of the ASM results in figure 3 display $\mathrm{H}_{\mathrm{O}}$-significance levels below 10 percent. Thus, even relatively poor temporal calibrations yield ASM results that are smaller than the typical values associated with randomly generated spectra. This emphasizes the uniqueness of the frequency arrangement associated with the orbital signal, and underscores a degree of similarity amongst the orbital parameters (for example, the ratio between the Cretaceous obliquity components is $\sim 1.3$, as is the ratio between the short eccentricity components).

A MODEL WITH VARIABLE SEDIMENTATION RATE

To evaluate the success of the ASM method under conditions of variable sedimentation, we introduce a second model with sedimentation rates ranging from $1.5 \mathrm{~cm} / \mathrm{kyr}$ to 2 $\mathrm{cm} / \mathrm{kyr}$ (an increase by 1/3). This model is 10 meters long with a sampling interval of $5 \mathrm{~cm}$, and is composed of the same seven mid-Cretaceous orbital components utilized in the first model (fig. 4A). MTM spectral analysis of the data series (fig. 4B) identifies four frequencies that exceed the 90 percent harmonic FSL: E1, an average of E2 and E3, an obliquity term, and a precession term. Thus, the changes in sedimentation rate within this interval do not permit identification of all the predicted orbital components.

The average spectral misfit result for these four frequencies (fig. 4C) identifies an optimal sedimentation rate of $1.75 \mathrm{~cm} / \mathrm{kyr}\left(\mathrm{ASM}=2.44 \times 10^{-3}\right.$ cycles $/ \mathrm{kyr}, 1.006 \%$

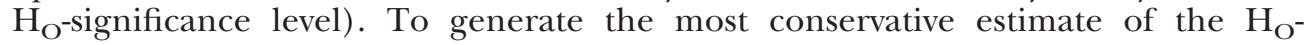
significance levels, this analysis (fig. 4D) utilizes 10 frequencies in the Monte Carlo simulation, based on a harmonic FSL of 90 percent. Note that the $\mathrm{H}_{\mathrm{O}}$-significance level at $1.75 \mathrm{~cm} / \mathrm{kyr}$ exceeds the critical significance level of 1.099 percent. Thus, we can reject the null hypothesis that the observed spectrum was derived from a random signal with a high degree of confidence. An alternative (less conservative) estimate of the $\mathrm{H}_{\mathrm{O}}$-significance levels is shown in figure 5, determined using 4 frequencies in the Monte Carlo spectra simulations. As expected, the analysis indicates a substantially lower $\mathrm{H}_{\mathrm{O}}$-significance level at $1.75 \mathrm{~cm} / \mathrm{kyr}(0.003 \%)$.

The above model highlights the fact that the ASM method is not compromised by substantial fluctuations in sedimentation $(<33 \%)$. More dramatic changes in sedimentation rate may require the use of a smaller window of analysis to achieve low $\mathrm{H}_{\mathrm{O}}$-significance levels. Alternatively, if the interval of analysis is too small, the resultant 

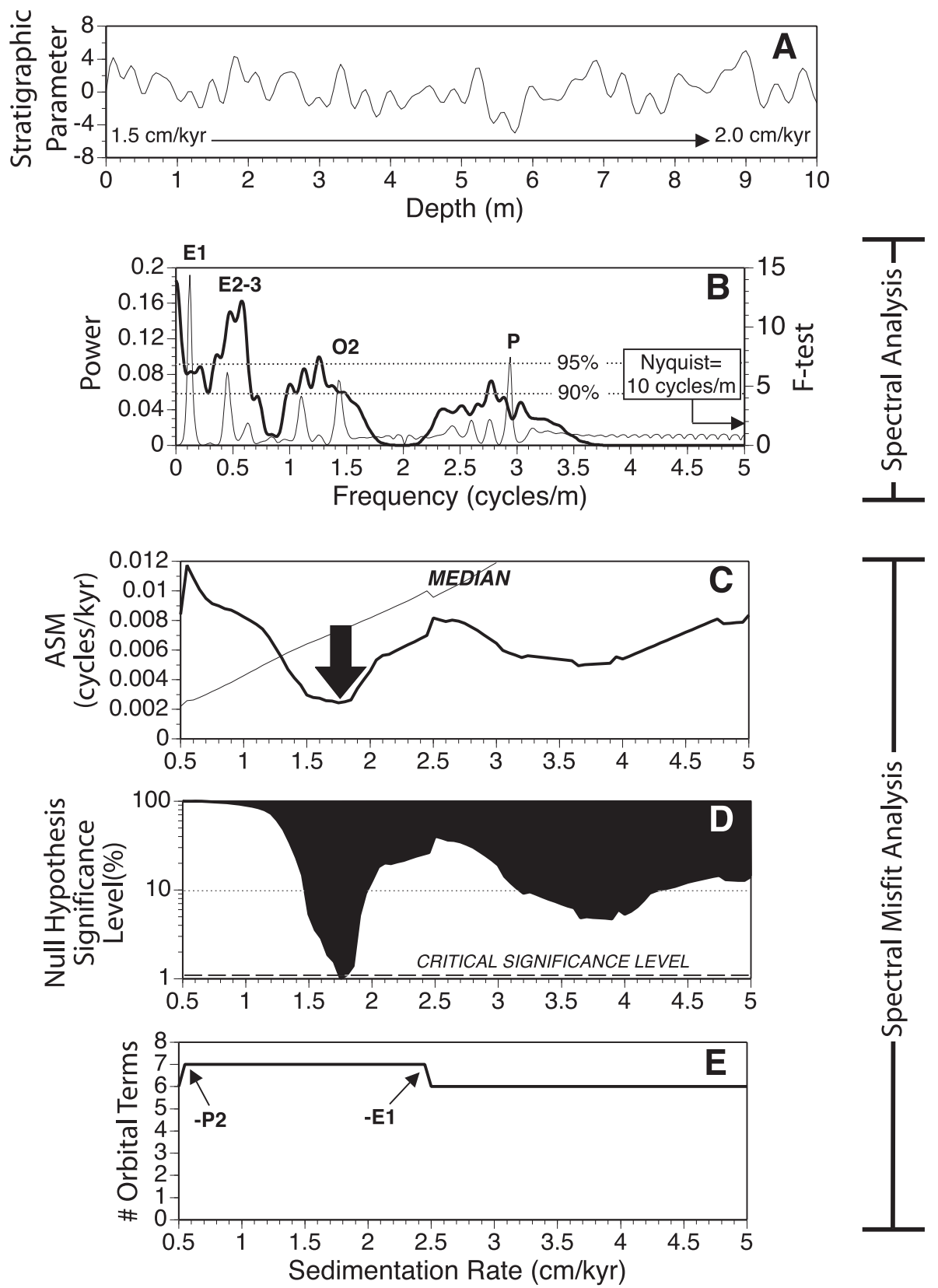

Fig. 4. (A) A 10-meter long stratigraphic model, generated to contain the seven predicted midCretaceous orbital components (E1, E2, E3, O1, O2, P1, P2) of Berger and others (1992), with a sedimentation rate increasing from $1.5 \mathrm{~cm} / \mathrm{kyr}$ to $2 \mathrm{~cm} / \mathrm{kyr}$, and a sampling interval of $5 \mathrm{~cm}$. The amplitude of each orbital period is unity. (B) Three-taper $2 \pi$ MTM power spectrum (thick bold line) and F-test results (thin line) for the model in figure 4A. Dotted lines indicate the $90 \%$ and $95 \%$ F-test significance levels. (C) Average spectral misfit results for the model (thick bold line), and the median ASM for each $\mathrm{H}_{\mathrm{O}}$-probability distribution (thin line). Beyond $3 \mathrm{~cm} / \mathrm{kyr}$, the median ASM exceeds 0.012 cycles $/ \mathrm{kyr}$. (D) $\mathrm{H}_{\mathrm{O}}$-significance levels for the model, calculated using 10 frequencies per spectrum and 100,000 simulated spectra. The dashed line indicates the critical significance level. (E) The number of Milankovitch terms that were available for calculation of ASM. See text for further discussion. 

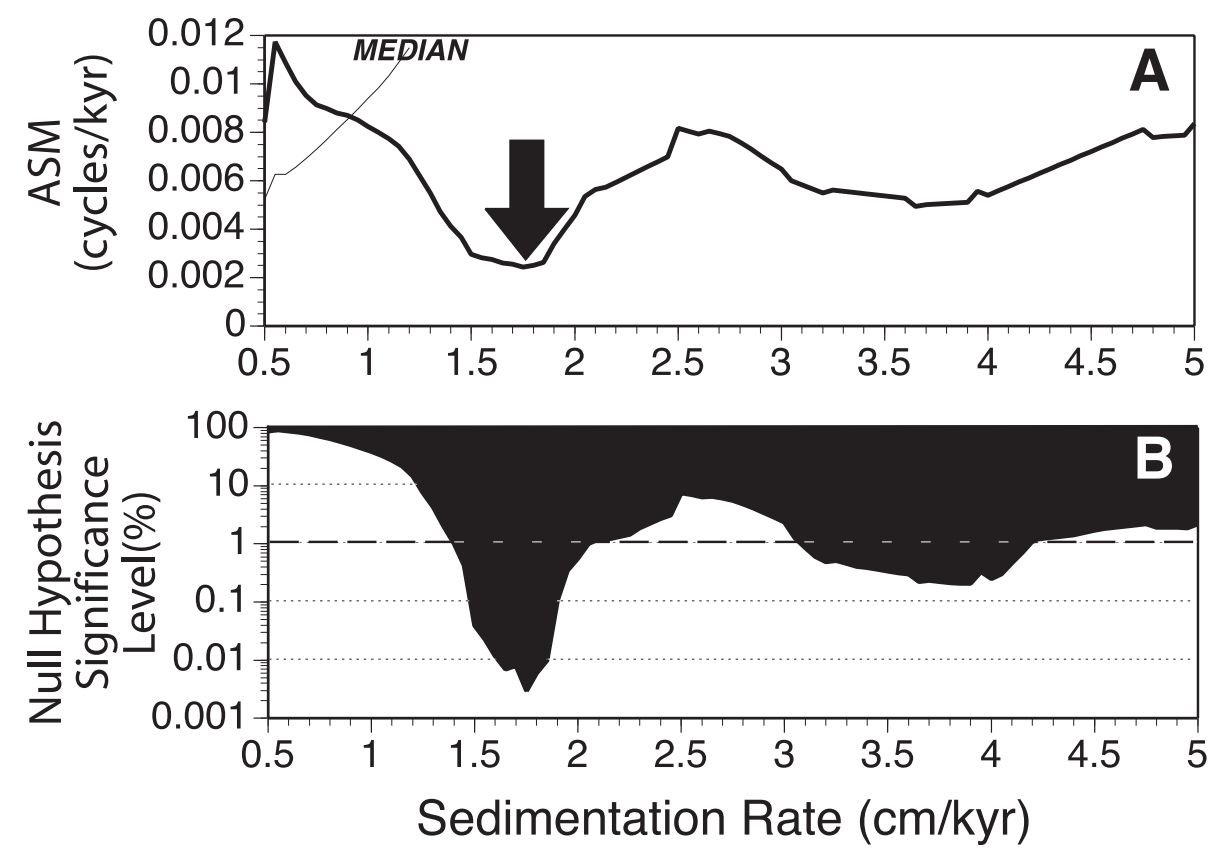

Fig. 5. (A) Average spectral misfit results for the model in figure 4A (thick bold line), and the median ASM for each $\mathrm{H}_{\mathrm{O}}$-probability distribution (thin line). Beyond $1.2 \mathrm{~cm} / \mathrm{kyr}$, the median ASM exceeds 0.012 cycles/kyr. (B) $\mathrm{H}_{\mathrm{O}}$-significance levels for the model, calculated using 4 frequencies per spectrum and 100,000 simulated spectra. The dashed line indicates the critical significance level. See text for further discussion.

decrease in frequency resolution can also negatively impact $\mathrm{H}_{\mathrm{O}}$-significance levels. Careful monitoring of the statistical results derived using a variety of window sizes should indicate whether or not a reliable orbital signal can be discerned from a given stratigraphic data series. In general, it is prudent to perform time-frequency analysis (for example, Park and Herbert, 1987; Meyers and others, 2001; Meyers and Sageman, 2004) prior to determining ASM, to identify intervals of sedimentation rate stability that are optimal for temporal calibration. Once the orbital signal is positively identified within a small stratigraphic interval, the orbital components may be "tracked" throughout the complete stratigraphic section using time-frequency analysis methods (for example, see Meyers and others, 2001).

\section{TESTING THE ORBITAL FORCING HYPOTHESIS IN THE UPPER BRIDGE CREEK LIMESTONE MEMBER}

One geologic interval that offers an excellent opportunity to test new cyclostratigraphic methods is the Late Cenomanian-Early Turonian $(\mathrm{C} / \mathrm{T})$. This interval is preserved in pelagic to hemipelagic settings in numerous locations globally (Arthur and others, 1987; Schlanger and others, 1987; Gale and others, 1993; Kuhnt and others, 1997), and many of these deposits are characterized by rhythmic bedding. $\mathrm{C} / \mathrm{T}$ strata also record a substantial excursion in $\delta^{13} \mathrm{C}$ of organic and inorganic carbon (for example, Scholle and Arthur, 1980; Pratt, 1985; Schlanger and others, 1987) that has been interpreted to reflect a global event of enhanced organic matter burial (Oceanic Anoxic Event II, or OAE II). Much recent work has focused on the development of high-resolution orbital time scales to calibrate the duration of this event, and to interpret rates of attendant paleoclimate and biogeochemical change (for example, Kauffman, 1995; Gale, 1995; Kuhnt and others, 1997; Gale and others, 2000; Meyers 
and others, 2001; Prokoph and others, 2001; Tsikos and others, 2004; Meyers and Sageman, 2004; Meyers and others, 2005; Sageman and others, 2006).

Mid-Cretaceous strata were first hypothesized to record orbitally-forced insolation changes by G. K. Gilbert (1895), based on his observations of the now famous rhythmic strata of the central Western Interior Basin, USA (WIB). Gilbert (1985) employed these lithologic rhythms to develop the first deep-time orbital timescale. Subsequent cyclostratigraphic work within the WIB remained largely dormant until a resurgence in the late-20 $0^{\text {th }}$ century following the detailed stratigraphic work of Hattin (1971) and the influential contributions of Fischer (1980). Much of this work focused on the limestonemarlstone couplets of the Bridge Creek Limestone Member $(\mathrm{C} / \mathrm{T})$, and included detailed stratigraphic and paleoecological analysis of the bedding rhythms (Fischer and others, 1985; Eicher and Diner, 1989; Watkins, 1989; Kauffman, 1995), geochemical analyses (Pratt, 1984, 1985; Elder, ms, 1987; Arthur and Dean, 1991; Orth and others, 1993), and GCM modeling (Barron and others, 1985; Glancy and others, 1993; Floegel and others, 2005).

Various orbital interpretations for the Bridge Creek rhythms have been proposed since Gilbert's (1895) original work. Most of these applied the ratio method (for example, Fischer, 1980; Pratt, 1985; Kauffman, 1995), but they have not converged on a common solution. Application of spectral analysis to quantify the Milankovitch orbital signature of the Bridge Creek Limestone Member was ultimately conducted by Sageman and others (1997). This study evaluated high-resolution $(\sim 5 \mathrm{~cm})$ geochemical and lithologic data from the USGS \#1 Portland core. Importantly, radiometrically dated bentonites from the WIB (Obradovich, 1993) provided temporal constraints for the development of integrated radiometric-biostratigraphic timescales (Kauffman and others, 1993; Gradstein and others, 1994), which Sageman and others (1997) employed to calibrate the observed spatial cycles to temporal periods. These timescales (Kauffman and others, 1993; Gradstein and others, 1994) indicated a range of plausible sedimentation rates between $0.35 \mathrm{~cm} / \mathrm{kyr}$ to $1.77 \mathrm{~cm} / \mathrm{kyr}$, given the timescale uncertainty.

Sageman and others (1997) focused their analysis on the upper Bridge Creek Limestone Member due to erratic spectral results from the lower portion of the unit. Based on observed spectral ratios and the available radiometric constraints, Sageman and others (1997) proposed a sedimentation rate of $0.6 \mathrm{~cm} / \mathrm{kyr}$, which yielded a good fit of observed bedding frequencies in the upper Bridge Creek to the orbital periods. This calibration resolved a stratigraphic signature containing precession, obliquity and eccentricity. Using Evolutive Harmonic Analysis, Meyers and others (2001) later confirmed that the lower Bridge Creek Limestone also preserves these orbital periodicities, but sedimentation rate changes severely distort the Milankovitch signal.

Prokoph and others (2001), in an alternative orbital interpretation of the Bridge Creek lithologic rhythms based on wavelet and spectral analysis of weight percent organic carbon data from Pratt and others (1993), proposed a sedimentation rate of $\sim 1.67 \mathrm{~cm} / \mathrm{kyr}$ for the study interval. Since this sedimentation rate estimate falls within the permissible range of values [based on the timescale of Kauffman and others (1993)], and yields temporal periods that are consistent with the predicted orbital frequencies, it provides a viable alternative. To evaluate this difference in estimated sedimentation rates (implying conflicting interpretations of the orbital signal) we revisit the high-resolution weight percent $\mathrm{CaCO}_{3}$ data series of Sageman and others (1997), and apply the new average spectral misfit metric.

Our analysis focuses on the upper 5.83 meters of strata (fig. 6A), because previous studies (Sageman and others, 1997; Meyers and others, 2001; Meyers and Sageman, 2004) suggest that the spatial bedding frequencies in the lower portion of the Bridge Creek Limestone are unstable due to marked sedimentation rate changes and hiatus. 


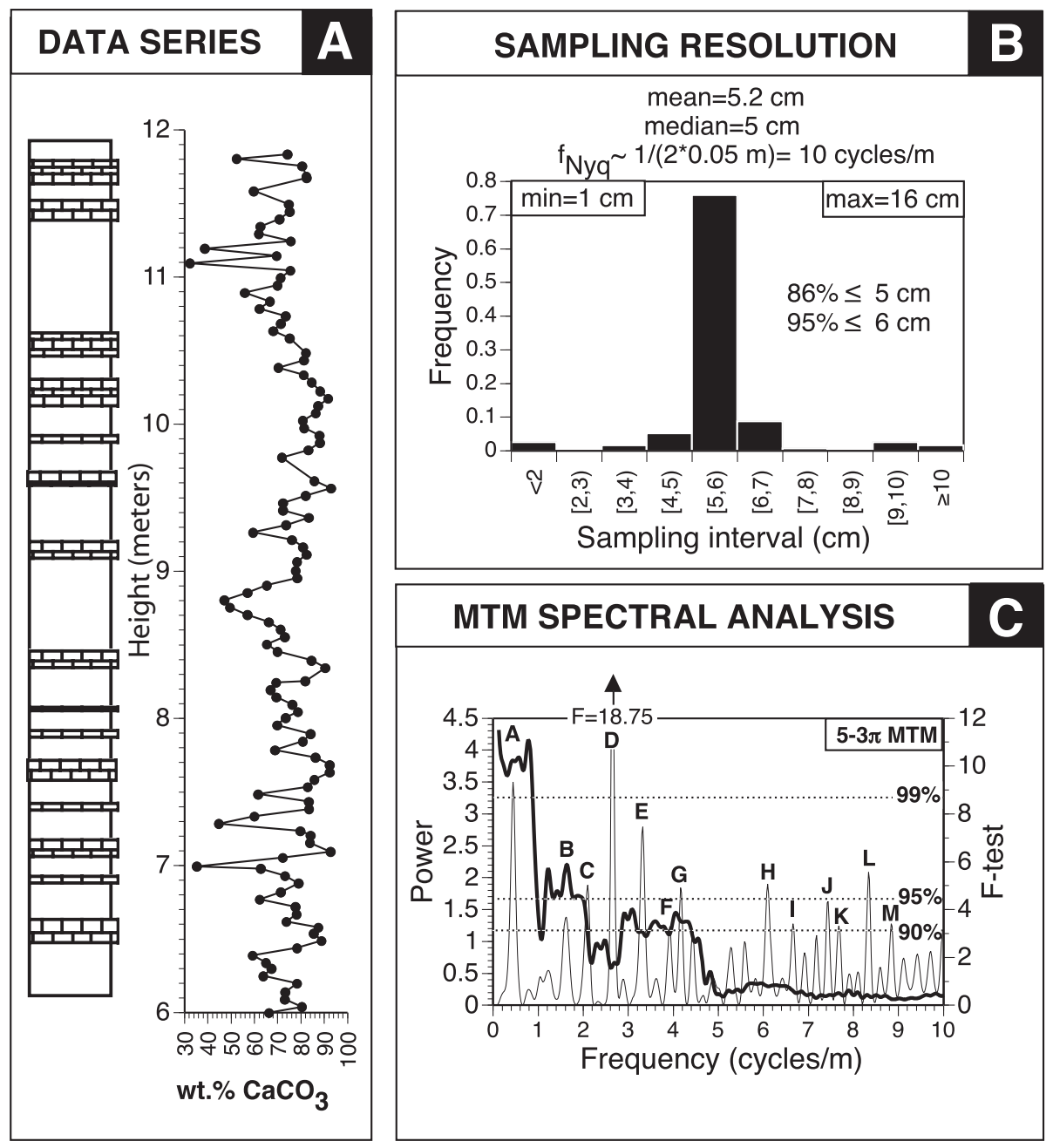

Fig. 6. (A) Stratigraphic column illustrating the decimeter to meter scale lithologic couplets of the uppermost Bridge Creek Limestone Member in the USGS \#1 Portland core, plotted with the wt. $\% \mathrm{CaCO}_{3}$ data of Sageman and others (1997). Note that the height scale has been corrected for bentonite removal. (B) Histogram of the wt.\% $\mathrm{CaCO}_{3}$ data sampling resolution, for the interval spanning 6 to 11.835 meters. (C) Five-taper $3 \pi$ MTM power spectrum (thick bold line) and F-test results (thin line) for the wt. $\% \mathrm{CaCO}_{3}$ in figure 6A (following interpolation to an even sample spacing, subtraction of the mean value and removal of a linear trend). Dashed lines indicate 90\%, 95\% and 99\% significance levels for the F-test results. Letters designate frequencies identified in table 1.

Following linear interpolation of the $\sim 5 \mathrm{~cm}$ resolution data (fig. $6 \mathrm{~B}$ ) to an even sample interval, MTM spectral analysis resolves thirteen highly significant ( $>90 \%$ F-test significance level) harmonic components (fig. 6C, table 1). The average spectral misfit results for these harmonic components identify a number of sedimentation rates associated with $\mathrm{H}_{\mathrm{O}}$-significance levels $<5$ percent (fig. 7A). A sedimentation rate of $0.61 \mathrm{~cm} / \mathrm{kyr}\left(\mathrm{ASM}=4.42 \times 10^{-4}\right.$ cycles $\left./ \mathrm{kyr}\right)$ is characterized by the lowest $\mathrm{H}_{\mathrm{O}^{-}}$ significance level $(0.11 \%)$, which surpasses the critical significance level of 0.55 percent. This calibration results in the temporal periods identified in table 1 . Three additional ASM values with $\mathrm{H}_{\mathrm{O}}$-significance level minima substantially below 5 percent 
TABLE 1

Summary of MTM spectral analysis results for wt. \% $\mathrm{CaCO}_{3}$ data from the upper Bridge Creek Limestone Member, and average spectral misfit results

\begin{tabular}{|c|c|c|c|c|c|c|}
\hline ID & $\begin{array}{l}\text { Frequency } \\
\text { (cycles/m) }\end{array}$ & $\begin{array}{c}\text { MTM } \\
\text { Probability }\end{array}$ & $\begin{array}{c}\text { Periodicity (kyr) } \\
\text { using } \\
\mathrm{s}=0.61 \mathrm{~cm} / \mathrm{kyr}\end{array}$ & $\begin{array}{c}\alpha_{k} \\
\text { (cycles/kyr) }\end{array}$ & $\begin{array}{c}\begin{array}{c}\text { Periodicity } \\
\text { (kyr) using } \\
\mathbf{s}=\mathbf{1 . 6 5} \mathrm{cm} / \mathrm{kyr}\end{array} \\
\end{array}$ & $\begin{array}{c}\alpha_{k} \\
(\text { cycles/kyr) }\end{array}$ \\
\hline $\mathbf{A}$ & 0.44 & $99.19 \%$ & $\begin{array}{c}\mathbf{3 7 2 . 5 8} \\
(462.59-311.89)\end{array}$ & $0(\mathrm{E} 1)$ & \begin{tabular}{|c|}
$\mathbf{1 3 7 . 7 4}$ \\
$(171.02-$ \\
$115.30)$ \\
\end{tabular} & $\begin{array}{c}0(\mathrm{E} 2) \\
3.29 \times 10^{-3} \\
(\mathrm{E} 3)\end{array}$ \\
\hline B & 1.62 & $92.67 \%$ & $\begin{array}{c}\mathbf{1 0 1 . 1 9} \\
(106.84-96.11)\end{array}$ & $\begin{array}{l}1.81 \times 10^{-3}(\mathrm{E} 2) \\
6.69 \times 10^{-4}(\mathrm{E} 3)\end{array}$ & $\begin{array}{c}\mathbf{3 7 . 4 1} \\
(39.50-35.53)\end{array}$ & $\begin{array}{c}6.90 \times 10^{-3} \\
(\mathrm{O} 1) \\
0(\mathrm{O} 2) \\
\end{array}$ \\
\hline $\mathrm{C}$ & 2.1 & $96.13 \%$ & $\begin{array}{c}78.06 \\
(81.38-75.01) \\
\end{array}$ & & $\begin{array}{c}28.86 \\
(30.09-27.73) \\
\end{array}$ & \\
\hline D & 2.64 & $99.90 \%$ & $\begin{array}{c}62.10 \\
(64.18-60.15) \\
\end{array}$ & & $\begin{array}{c}\mathbf{2 2 . 9 6} \\
(23.73-22.24) \\
\end{array}$ & $0(\mathrm{P} 1)$ \\
\hline $\mathbf{E}$ & 3.32 & $98.52 \%$ & $\begin{array}{c}\mathbf{4 9 . 3 8} \\
(50.68-48.14) \\
\end{array}$ & $0(\mathrm{O} 1)$ & $\begin{array}{c}\mathbf{1 8 . 2 5} \\
(18.74-17.80) \\
\end{array}$ & $0(\mathrm{P} 2)$ \\
\hline $\mathbf{F}$ & 3.92 & $90.99 \%$ & $\begin{array}{c}41.82 \\
(42.75-40.93)\end{array}$ & & $\begin{array}{c}15.46 \\
(15.81-15.13)\end{array}$ & \\
\hline G & 4.16 & $95.95 \%$ & $\begin{array}{c}\text { 39.41 } \\
(40.24-38.61)\end{array}$ & $0(\mathrm{O} 2)$ & $\begin{array}{c}14.57 \\
(14.87-14.27)\end{array}$ & \\
\hline $\mathbf{H}$ & 6.1 & $96.20 \%$ & $\begin{array}{c}26.87 \\
(27.26-26.50) \\
\end{array}$ & & $\begin{array}{c}9.94 \\
(10.08-9.80) \\
\end{array}$ & \\
\hline I & 6.66 & $91.50 \%$ & $\begin{array}{c}24.61 \\
(24.94-24.30) \\
\end{array}$ & & $\begin{array}{c}9.10 \\
(9.22-8.98) \\
\end{array}$ & \\
\hline $\mathbf{J}$ & 7.44 & $94.71 \%$ & $\begin{array}{c}\mathbf{2 2 . 0 3} \\
(22.29-21.78) \\
\end{array}$ & $6.21 \times 10^{-4}(\mathrm{P} 1)$ & $\begin{array}{c}8.15 \\
(8.24-8.05) \\
\end{array}$ & \\
\hline $\mathbf{K}$ & 7.68 & $91.05 \%$ & $\begin{array}{c}21.35 \\
(21.59-21.11) \\
\end{array}$ & & $\begin{array}{c}7.89 \\
(7.98-7.80) \\
\end{array}$ & \\
\hline $\mathbf{L}$ & 8.34 & $96.95 \%$ & $\begin{array}{c}19.66 \\
(19.86-19.46) \\
\end{array}$ & & $\begin{array}{c}7.27 \\
(7.34-7.19)\end{array}$ & \\
\hline M & 8.84 & $91.53 \%$ & $\begin{array}{c}\mathbf{1 8 . 5 4} \\
(18.73-18.37) \\
\end{array}$ & $0(\mathrm{P} 2)$ & $\begin{array}{c}6.86 \\
(6.92-6.79) \\
\end{array}$ & \\
\hline & $\Sigma \alpha_{k}$ & & & $3.10 \times 10^{-3}$ & & $1.02 \times 10^{-2}$ \\
\hline & $\mathbf{n}$ & & & 7 & & 6 \\
\hline & ASM & & & $\begin{array}{l}4.42 \times 10^{-4} \\
\text { cycles } / \mathrm{kyr}\end{array}$ & & $\begin{array}{l}1.70 \times 10^{-3} \\
\text { cycles } / \mathrm{kyr}\end{array}$ \\
\hline & $\begin{array}{l}\text { Null Hyp. } \\
\text { Sig. Level }\end{array}$ & & & $0.11 \%$ & & $3.22 \%$ \\
\hline
\end{tabular}

The MTM spectrum was calculated using five $3 \pi$ tapers (Thomson, 1982). Average spectral misfit was calculated using $\Delta \mathrm{f}_{\mathrm{R}}=0.171232877$ cycles $/$ meter, and $\mathrm{f}_{\mathrm{Ny}}=10$ cycles $/$ meter. Null hypothesis significance levels were determined using 13 frequencies and 100,000 random spectra. Temporal periodicities in parentheses represent the F-test minimum resolution bandwidth (see Appendix), and the "ID" column refers to the peaks designated in figures 6 and 8.

occur at sedimentation rates of $0.65 \mathrm{~cm} / \mathrm{kyr}\left(\mathrm{ASM}=8.12 \times 10^{-4}\right.$ cycles $/ \mathrm{kyr}, \mathrm{H}_{\mathrm{O}^{-}}$ significance level $=1.31 \%), 0.73 \mathrm{~cm} / \mathrm{kyr}\left(\mathrm{ASM}=1.03 \times 10^{-3}\right.$ cycles $/ \mathrm{kyr}, \mathrm{H}_{\mathrm{O}^{-} \text {-significance }}$ level $=2.45 \%)$, and $1.65 \mathrm{~cm} / \mathrm{kyr}\left(\mathrm{ASM}=1.70 \mathrm{E}-03\right.$ cycles $/ \mathrm{kyr}, \mathrm{H}_{\mathrm{O}}$-significance level $=3.22 \%$ ) (figs. $7 \mathrm{~A}$ and $7 \mathrm{~B}$ ). The highest of these sedimentation rates $(1.65$ $\mathrm{cm} / \mathrm{kyr}$ ) is consistent with Prokoph and others (2001) estimate, and results in the second orbital interpretation displayed in table 1 . Based on this analysis, we conclude 

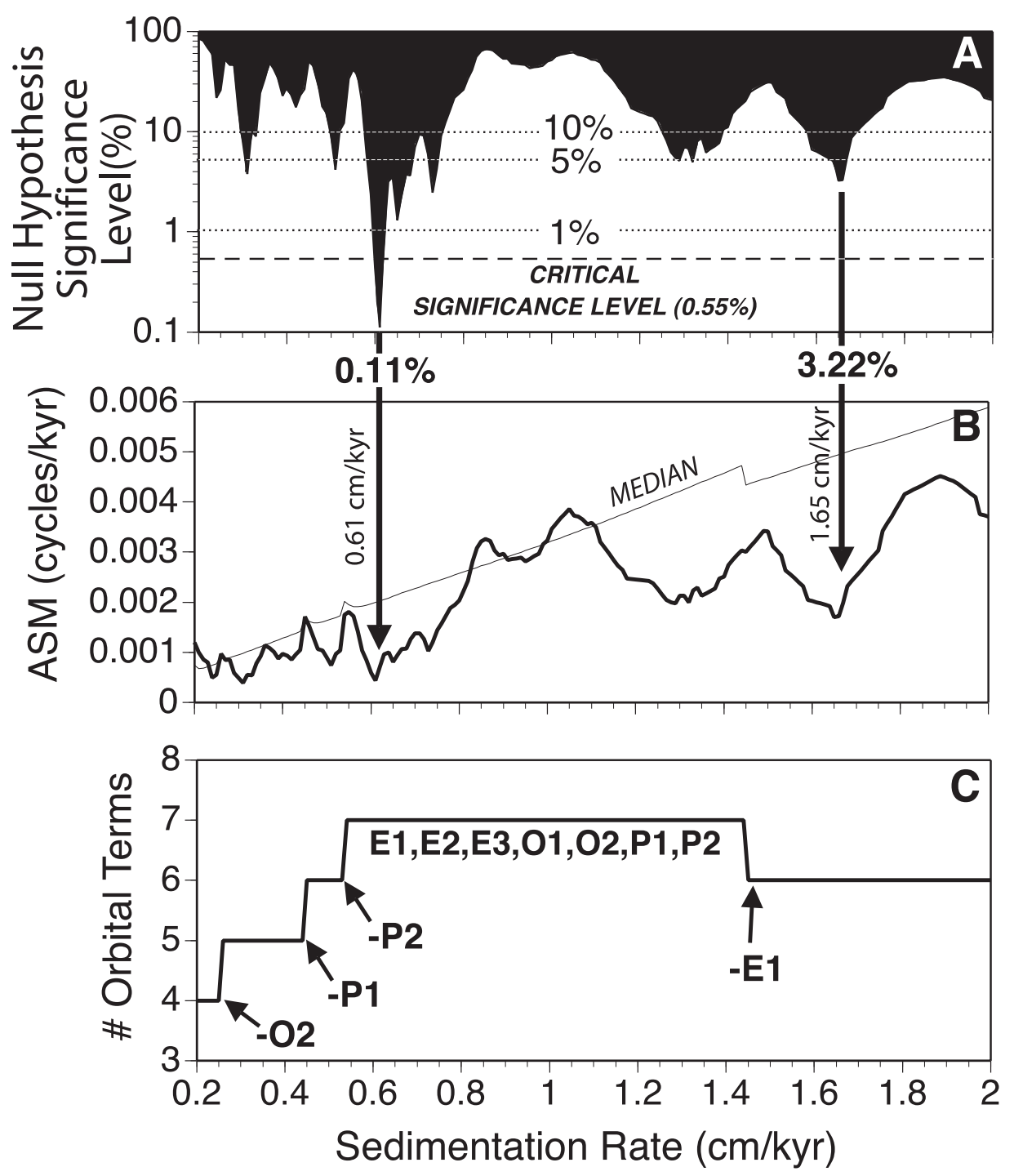

Fig. 7. (A) $\mathrm{H}_{\mathrm{O}}$-significance levels for the ASM results in figure $7 \mathrm{~B}$, calculated using 13 frequencies per spectrum and 100,000 simulated spectra. The dashed line indicates the critical significance level. (B) ASM results for the spectrum in figure 6C (bold line), and the median ASM for each $\mathrm{H}_{\mathrm{O}}$-probability distribution (dashed line). (C) The number of Milankovitch terms that were available for calculation of ASM. See text for further discussion.

that the $0.61 \mathrm{~cm} /$ kyr calibration yields the optimal fit between observed and predicted orbital periods, providing supporting evidence for the orbital interpretation of Sageman and others (1997). There is only a 0.11 percent probability that such a low ASM value could be derived by chance.

As indicated by the $0.61 \mathrm{~cm} / \mathrm{kyr}$ calibrated periods in table 1 , the weight percent $\mathrm{CaCO}_{3}$ data from the upper Bridge Creek Limestone Member is characterized by numerous periodicities in the range of precession $(18.54,19.66,21.35,22.03)$ and obliquity $(39.41,41.82,49.38,62.10)$, far in excess of those predicted by orbital theory. 


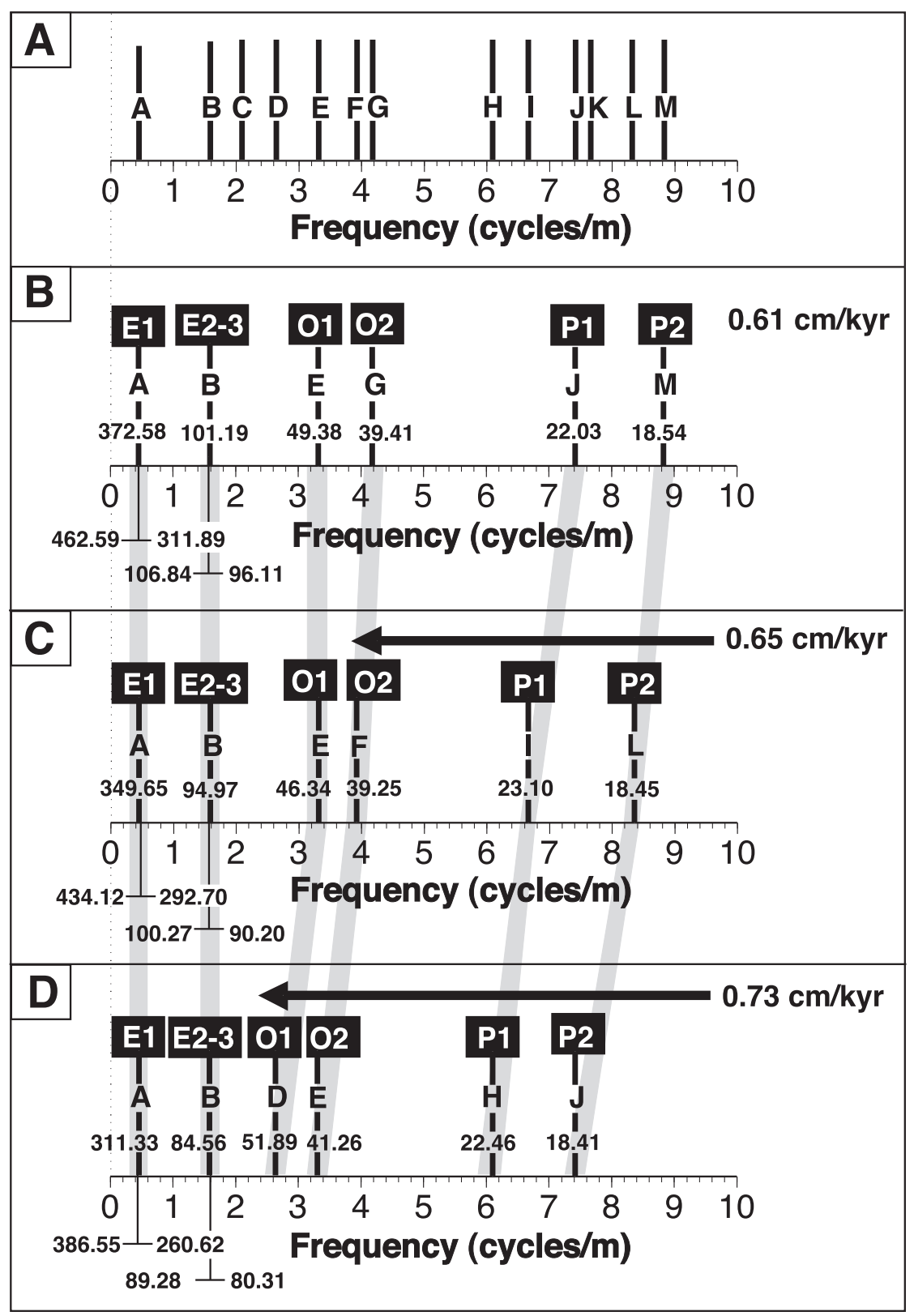

Fig. 8. (A) Significant harmonic components identified by MTM spectral analysis. Letters refer to spatial frequencies designated in figure $6 \mathrm{C}$ and table 1 . (B) Harmonic components reflecting orbital periods recorded at a sedimentation rate of $0.61 \mathrm{~cm} / \mathrm{kyr}\left(\mathrm{ASM}=4.42 \times 10^{-4}\right.$ cycles $/ \mathrm{kyr}, \mathrm{H}_{\mathrm{O}}$-significance level $\left.=0.11 \%\right)$. (C) Harmonic components reflecting orbital periods recorded at a sedimentation rate of $0.65 \mathrm{~cm} / \mathrm{kyr}$ (ASM= $8.12 \times 10^{-4}$ cycles $/ \mathrm{kyr}, \mathrm{H}_{\mathrm{O}}$-significance level=1.31\%). (D) Harmonic components reflecting orbital periods recorded at a sedimentation rate of $0.73 \mathrm{~cm} / \mathrm{kyr}\left(\mathrm{ASM}=1.03 \times 10^{-3}\right.$ cycles $/ \mathrm{kyr}, \mathrm{H}_{\mathrm{O}}$-significance level $\left.=2.45 \%\right)$.

This is a consequence of minor sedimentation rate changes throughout the upper Bridge Creek Limestone, as originally documented by Meyers and others (2001) using time-frequency analysis. Given the variability in sedimentation rate identified by 
Meyers and others (2001) (from 0.51 to $0.84 \mathrm{~cm} / \mathrm{kyr}$ ) a primary orbital origin can account for most of the observed harmonics in the uppermost Bridge Creek Limestone Member (fig. 8). This variability in sedimentation is also suggested by a clustering of ASM values with very low $\mathrm{H}_{\mathrm{O}}$-significance levels between 0.60 to $0.75 \mathrm{~cm} / \mathrm{kyr}$ (fig. $7 \mathrm{~A}$ ). The relationship between these changes in sedimentation rate and the origin of the observed bedding periods is displayed in figure 8 . Finally, the average sedimentation rate for the interval $(0.61 \mathrm{~cm} / \mathrm{kyr})$ is independently confirmed by other methods (Meyers and others, 2001).

\section{CONCLUSIONS}

This study introduces a new metric for the temporal calibration of spatial rhythms hypothesized to reflect an orbital signal. A unique contribution of this new approach is the incorporation of an explicit statistical test for rejection of the null hypothesis of no orbital forcing. The method does not require radiometric data for calibration, and provides a consistent standard by which orbital timescales developed in different studies may be evaluated and compared. Thus, as new data and refined geochemical analytical methods become available, average spectral misfit and $\mathrm{H}_{\mathrm{O}}$-significance levels provide an impartial approach for comparing old and new orbital interpretations. To test the method we analyzed a published weight percent $\mathrm{CaCO}_{3}$ record from the Bridge Creek Limestone Member (Sageman and others, 1997). The minimum misfit analysis helps resolve a standing debate about the nature of the Bridge Creek bedding cycles and yields strong confirmation that the preserved rhythms are attributable to orbital forcing. Computer code for calculation of average spectral misfit and $\mathrm{H}_{\mathrm{O}^{-}}$ significance levels is available for download at http://www.unc.edu/ smeyers/ software.html.

\section{ACKNOWLEDGMENTS}

This study was supported by National Science Foundation grant EAR-0001093 (BBS) and the Yale Institute for Biospheric Studies Gaylord Donnelley Environmental Fellowship (SRM). We also acknowledge insightful comments provided by Jonathan Lees, Roy Plotnick, and an anonymous reviewer.

APPENDix

THEORETICAL BACKGROUND OF THE AVERAGE SPECTRAL MISFIT METRIC

The rationale for the new misfit parameter has its roots in the fundamental limitations of spectral analysis techniques. Therefore, we begin by defining some of the basic properties of the Fast Fourier Transform (FFT) upon which most spectral analysis methods are based. To begin, the frequency grid spacing $(\Delta \mathrm{f})$ of the FFT of a data series is:

$$
\Delta \mathrm{f}=1 /\left(\mathrm{N}^{*} \Delta \mathrm{x}\right)
$$

$\mathrm{N}$ : Number of points in data series

$\Delta \mathrm{x}$ : Sampling resolution of data series

Data series are typically "padded" with zeros to satisfy FFT requirements (for example, the time series must be of a length equivalent to a power of 2) and/or to decrease $\Delta \mathrm{f}$. Such zero-padding of the data series decreases the frequency grid mesh, and provides the opportunity for more accurate location of the identified components (for example, the true frequency may be intermediate between the original $\Delta \mathrm{f}$ values), but this practice does not increase the inherent bandwidth resolution of the analysis. We will henceforth refer to the pre-padded $\Delta \mathrm{f}$ as the Rayleigh spacing $\left(\Delta \mathrm{f}_{\mathrm{R}}\right)$, and the post-padded $\Delta \mathrm{f}$ as the FFT bin spacing $\left(\Delta \mathrm{f}_{\mathrm{FFT}}\right)$.

The maximum resolvable frequency (the Nyquist frequency, $\mathrm{f}_{\mathrm{Nyq}}$ ) is defined as:

$$
\mathrm{f}_{\mathrm{Nyq}}=1 /(2 * \Delta \mathrm{x})
$$


Thus, the maximum number of independent discrete positive frequencies that we can assess via Fourier analysis is $\left(\mathrm{f}_{\mathrm{Nyq}} / \Delta \mathrm{f}_{\mathrm{R}}\right)$. We use the Multi-taper method (MTM) of Thomson (1982) to conduct this Fourier analysis. Importantly, the MTM provides a statistical test for the presence of pure sinusoidal components in stratigraphic data series. This significance test is independent of amplitude, so it can identify certain low amplitude peaks that are statistically significant, as well as certain high amplitude peaks that are not. This property makes the MTM technique of particular value for detection of orbital cycles in settings where the insolation signal has been severely altered via the orbital-insolation transfer functions. For example, even if power has been almost completely transferred from a carrier frequency (precession) into its modulator (eccentricity) (for example, Ripepe and Fischer, 1991), the MTM technique provides the opportunity to accurately identify the presence of the original precession signal.

Thomson (1990) notes, "Empirical evidence suggests that the F-test works well down to the Rayleigh resolution, $1 /\left(\mathrm{N}^{*} \Delta \mathrm{x}\right)$, but if lines are spaced closer than this the test rapidly breaks down." A traditional measure of this limit is the minimum resolution bandwidth (Harris, 1978), which is defined as "the minimum separation between two equal strength lines such that for arbitrary spectral locations their respective main [amplitude] lobes can be resolved." In stratigraphic records of orbital cyclicity such closely spaced line components may be present due to several factors: (1) each of the dominant precession (P1, P2), obliquity $(\mathrm{O} 1, \mathrm{O} 2)$ and eccentricity $(\mathrm{E} 1, \mathrm{E} 2, \mathrm{E} 3)$ insolation quasi-periods are themselves composed of closely spaced harmonic lines (Berger, 1978; Hinnov, 2000), (2) sedimentation rate changes in the interval may result in non-stationarity that generates many closely spaced line components, and (3) very short data records may contain more than one quasi-period within the same $\Delta \mathrm{f}_{\mathrm{R}}$ bin (for example, $\mathrm{E} 2$ and E3, O1 and $\mathrm{O} 2$, and/or P1 and P2). The maximum resolution that we can hope to achieve in the analysis of such data series is limited to $\Delta \mathrm{f}_{\mathrm{R}}$, and this resolution limit must be considered in our misfit analysis.

Once the significant harmonic components have been identified via MTM spectral analysis, these frequencies are calibrated using a range of sedimentation rates $(f * s)$, and a tolerance of $+/-0.5 * \Delta f_{R} *_{s}$ is assigned to each frequency to account for the minimum resolution bandwidth of the spectrum (the fact that multiple line components within this range will be averaged into one). The spectral misfit analysis is accomplished by mapping the expected locations of the predicted precession, obliquity and eccentricity components into the calibrated amplitude spectrum. If the tolerance $\left(+/-0.5 * \Delta f_{R} *_{s}\right)$ of the nearest measured significant harmonic component captures the predicted orbital frequency, $\alpha_{\mathrm{k}}$ (eq. 1) is assigned a value of zero, a perfect fit given the resolution of the spectrum. If this tolerance does not capture the orbital frequency, we calculate the distance between the closest significant line component and the predicted frequency. These $\alpha_{\mathrm{k}}$ are summed across all " $n$ " orbital frequencies and divided by " $n$ " to calculate an average misfit (eq. 1). Only those orbital periods that are resolvable, given the particular temporal calibration, are employed in the ASM analysis (frequencies ranging from $\Delta f_{R}{ }^{*} s$ to $f_{N y q}{ }^{*} s$ ).

Additional criteria that may be employed in the application of the misfit metric include the requirement of persistent spatial bedding frequencies throughout the stratigraphic data series (as identified via timefrequency analysis), jackknife error estimation of frequency location (for example, Park and Herbert, 1987; Thomson and Chave, 1991), requirement of a minimum power level (for example, Mann and Lees, 1996), and incorporation of potential aliased orbital signal locations in the misfit analysis.

\section{REFERENCES}

Arthur, M. A., and Dean, W. E., 1991, An holistic geochemical approach to cyclomania: Examples from Cretaceous pelagic limestone sequences, in Einsele, G., Ricken, W., and Seilacher, A., editors, Cycles and Events in Stratigraphy: Berlin, Springer-Verlag, p. 126-166.

Arthur, M. A., Schlanger, S. O., and Jenkyns, H. C., 1987, The Cenomanian-Turonian Oceanic Anoxic Event II. Paleoceanographic controls on organic matter production and preservation, in Brooks, J., and Fleet, A., editors, Marine Petroleum Source Rocks: London, Geological Society Special Publication, v. 26, p. $401-420$

Barron, E. J., Arthur, M. A., and Kauffman, E. G., 1985, Cretaceous rhythmic bedding sequences: A plausible link between orbital variations and climate: Earth and Planetary Science Letters, v. 72, p. 327-340.

Berger, A., 1978, Long-term variations of daily insolation and Quaternary climate change: Journal of Atmospheric Sciences, v. 35, p. 2362-2367.

Berger, A., and Pestiaux, P., 1984, Accuracy and stability of the Quaternary terrestrial insolation, in Berger, A., Imbrie, J., Hays, J., Kukla, G., and Saltzman, B., editors, Milankovitch and Climate: Understanding the Response to Astronomical Forcing: Hingham, Massachusetts, D. Reidel Publishing Company, p. 83-112.

Berger, A., Loutre, M. F., and Laskar, J., 1992, Stability of the astronomical frequencies over the Earth's history for paleoclimate studies: Science, v. 255, p. 560-566.

D'Argenio, B., Ferreri, B., Amodio, S., and Pelosi, N., 1997, Hierarchy of high-frequency orbital cycles in Cretaceous carbonate platform strata: Sedimentary Geology, v. 113, p. 169-193. 
de Menocal, P. B., 1995, Plio-Pleistocene African climate: Science, v. 270. p. 53-59.

Eicher, D. L., and Diner, R., 1989, Origin of the Cretaceous Bridge Creek cycles in the Western Interior, United States: Palaeogeography, Palaeoclimatology, Palaeoecology, v. 74, p. 127-146.

Elder, W. P., ms, 1987, Cenomanian-Turonian (Cretaceous) stage boundary extinctions in the Western Interior of the United States: Boulder, Colorado, University of Colorado, Ph. D. thesis, $621 \mathrm{p}$.

Fischer, A. G., 1980, Gilbert-bedding rhythms and geochronology, in Yochelson, E. I., editor, The Scientific Ideas of G. K. Gilbert: Geological Society of America, Special Paper 183, p. 93-104.

Fischer, A. G., Herbert, T., and Premoli-Silva, I., 1985, Carbonate bedding cycles in Cretaceous pelagic and hemipelagic sediments, in Pratt, L. M., Kauffman, E. G., and Zelt, F. B., editors, Fine-Grained Deposits and Biofacies of the Cretaceous Western Interior Seaway: Evidence of Cyclic Sedimentary Processes: SEPM, Field Trip Guidebook 4, p. 1-10.

Flogel, S., Hay, W. W., DeConto, R. M., and Balukhovsky, A. N., 2005, Formation of sedimentary bedding couplets in the Western Interior Seaway of North America- implications for climate system modeling: Palaeogeography, Palaeoclimatology, Palaeoecology, v. 218, p. 125-143.

Gale, A. S., 1995, Cyclostratigraphy and correlation of the Cenomanian Stage in western Europe, in House, M. R., and Gale, A. S., editors, Orbital Forcing Timescales and Cyclostratigraphy: London, Geological Society, Special Publication, v. 85, p. 177-198.

Gale, A. S., Jenkyns, H. C., Kennedy, W. J., and Corfield, R. M., 1993, Chemostratigraphy vs. biostratigraphy: data from around the Cenomanian-Turonian boundary: London, Journal of the Geological Society, v. 150, p. 29-32.

Gale, A. S., Smith, A. B., Monks, N. E. A., Young, J. A., Howard, A., Wray, D. S., and Hugget, J. M., 2000, Marine biodiversity through the late Cenomanian-early Turonian; palaeoceanographic controls and sequence stratigraphic biases: London, Journal of the Geological Society, v. 157, p. 745-757.

Gilbert, G. K., 1895, Sedimentary measurement of geologic time: Geology, v. 3, p. 121-127.

Glancy, T. J., Jr., Arthur, M. A., Barron, E. J., and Kauffman, E. G., 1993, A paleoclimate model for the North American Cretaceous (Cenomanian-Turonian) epicontinental sea, in Caldwell, W. G. E., and Kauffman, E. G., editors, Evolution of the Western Interior Basin: Geological Association of Canada, Special Paper 39 , p. 219-242.

Goldhammer, R. K., Dunn, P. A., and Hardie, L. A., 1990, Depositional cycles, composite sea-level changes, cycle stacking-patterns, and the hierarchy of stratigraphic forcing: Examples from Alpine Triassic platform carbonates: Geological Society of America, Bulletin, v. 102, p. 535-562.

Gradstein, F. M., Agterberg, F. P., Ogg, J. G., Hardenbol, J., van Veen, P., Jacques, T., and Huang, Z., 1994, A Mesozoic time scale: Journal of Geophysical Research, v. 99, p. 24,051-24,074.

Gradstein, F., Ogg, J., and Smith, A., 2004, A geologic time scale: Cambridge, Cambridge University Press, $589 \mathrm{p}$.

Harris, F. J., 1978, On the use of windows for harmonic analysis with the discrete Fourier transform: Proceedings of the IEEE, v. 66, p. 51-83.

Hattin, D. E., 1971, Widespread, synchronously deposited, burrow-mottled limestone beds in Greenhorn Limestone (Upper Cretaceous) of Kansas and central Colorado: American Association Petroleum Geologists Bulletin, v. 55, p. 412-431.

Herbert, T. D., 1992, Paleomagnetic calibration of Milankovitch cyclicity in Lower Cretaceous sediments: Earth and Planetary Science Letters, v. 112, p. 15-28.

Herbert, T. D., and Fischer, A. G., 1986, Milankovitch climatic origin of mid-Cretaceous black shale rhythms in central Italy: Nature, v. 321, p. 739-743.

Hinnov, L. A., 2000. New perspectives on orbitally forced stratigraphy: Annual Review of Earth and Planetary Sciences, v. 28 , p. $419-475$.

Hinnov, L. A., and Park, J. J., 1998, Detection of astronomical cycles in the stratigraphic record by frequency modulation (FM) analysis: Journal of Sedimentary Research, v. 68, p. 524-539.

Hinnov, L. A., Park, J., and Erba, E., 2000, Lower-Middle Jurassic rhythmites from the Lombard Basin, Italy: a record of orbitally forced carbonate cycles modulated by secular environmental changes in West Tethys, in Hall, R. L., and Smith, P. L., editors, Advances in Jurassic Research 2000: Zurich, Switzerland, GeoResearch Forum, v. 6, Trans Tech Publications, p. 427-436.

Kauffman, E. G., 1995, Global change leading to biodiversity crisis in a greenhouse world: The CenomanianTuronian (Cretaceous) Mass Extinction, in Stanley, S., editor, Effects of Past Global Change on Life: Washington D. C., National Research Council, National Academy Press, p. 47-71.

Kauffman, E. G., Sageman, B. B., Elder, W. P., Kirkland, J. I., and Villamil, T., 1993, Cretaceous molluscan biostratigraphy and biogeography, Western Interior Basin, North America, in Caldwell,W. G. E., and Kauffman, E. G., editors, Evolution of the Western Interior Basin: Geological Association of Canada, Special Paper 39, p. 397-434.

Kennedy, W. J., and Cobban, W. A., 1991, Stratigraphy and interregional correlation of the CenomanianTuronian transition in the Western Interior of the United States near Pueblo, Colorado, a potential boundary stratotype for the base of the Turonian stage: Newsletters in Stratigraphy, v. 24 (1/2), p. 1-33.

Kennedy, W. J., Walaszczyk, I., and Cobban, W. A., 2000, Pueblo, Colorado, USA, candidate Global Boundary Stratotype Section and Point for the base of the Turonian stage of the Cretaceous, and for the base of the middle Turonian substage, with a revision of the Inoceramidae (Bivalvia): Acta Geologica Polonica, v. 50, p. 295-334.

Kominz, M. A., and Bond, G. C., 1990, A new method of testing periodicity in cyclic sediments: application to the Newark Supergroup: Earth and Planetary Science Letters, v. 98, p. 233-244.

Kuhnt, W., Nederbragt, A., and Leine, L., 1997, Cyclicity of Cenomanian-Turonian organic-carbon-rich sediments in the Tarfaya Atlantic Coastal Basin (Morocco): Cretaceous Research, v. 18, p. 587-601. 
Laskar, J., Robutel1, P., Joutel1, F., Gastineau1, M., Correia1, A. C. M., and Levrard, B., 2004, A long-term numerical solution for the insolation quantities of the Earth: Astronomy and Astrophysics, v . 428, p. 261-285.

Mann, M. E., and Lees, J. M., 1996, Robust estimation of background noise and signal detection in climatic time series: Climate Change, v. 33, p. 409-445.

Meyers, S. R., and Sageman, B. B., 2004, Detection, quantification, and significance of hiatuses in pelagic and hemipelagic strata: Earth and Planetary Science Letters, v. 224, p. 55-72.

Meyers, S., Sageman, B., and Hinnov, L., 2001, Integrated quantitative stratigraphy of the CenomanianTuronian Bridge Creek Limestone Member using Evolutive Harmonic Analysis and stratigraphic modeling: Journal of Sedimentary Research, v. 71, p. 627-643.

Meyers, S. R., Sageman, B. B., and Lyons, T., 2005, Organic carbon burial rate and the molybdenum proxy: Theoretical framework and application to Cenomanian-Turonian OAE II: Paleoceanography, PA2002, doi:10.1029/2004PA001068.

Obradovich, J., 1993, A Cretaceous time scale, in Caldwell, W. G. E., and Kauffman, E. G., editors, Evolution of the Western Interior Basin: Geological Society of Canada, Special Paper 39, p. 379-396.

Olsen, P. E., 1986, A 40-million year lake record of early Mesozoic orbital climatic forcing: Science, v. 234, p. $842-848$.

Orth, C. J., Attrep, M., Jr., Quintana, L. R., Elder, W. P., Kauffman, E. G., Diner, R., and Villamil, T., 1993, Elemental abundances in the late Cenomanian extinction interval; a search for the source(s): Earth and Planetary Science Letters, v. 117, p. 189-204.

Park, J., and Herbert, T., 1987, Hunting for paleoclimatic periodicities in a geologic time series with an uncertain time scale: Journal of Geophysical Research, v. 92, p. 14,027-14,040.

Park, J., and Oglesby, R. J., 1991, Milankovitch rhythms in the Cretaceous: A GCM modeling study: Paleogeography, Palaeoclimatology, Palaeoecology (Global and Planetary Change), v. 90, p. 329-355.

Park, J., D'Hondt, S. L., King, J. W., and Gibson, C., 1993, Late Cretaceous precessional cycles in double time: A warm-earth Milankovitch response: Science, v. 261, p. 1431-1434.

Pratt, L. M., 1984, Influence of paleoenvironmental factors on the preservation of organic matter in middle Cretaceous Greenhorn Formation near Pueblo, Colorado: American Association of Petroleum Geologists, Bulletin, v. 68, p. 1146-1159.

1985, Isotopic studies of organic matter and carbonate in rocks of the Greenhorn Marine Cycle, in Pratt, L. M., Kauffman, E. G., and Zelt, F. B., editors, Fine-Grained Deposits and Biofacies of the Cretaceous Western Interior Seaway: Evidence of Cyclic Sedimentary Processes: SEPM, Field Trip Guidebook No. 4, p. 38-48.

Pratt, L., Arthur, M., Dean, W., and Scholle, P., 1993, Paleoceanographic cycles and events during the late Cretaceous in the Western Interior Seaway of North America, in Caldwell, W. G. E., and Kauffman, E. G., editors, The Evolution of the Western Interior Basin: Geological Association of Canada, Special Paper 39, p. 333-353.

Prokoph, A., Villeneuve, M., Agterberg, F. P., and Rachold, V., 2001, Geochronology and calibration of global Milankovitch cyclicity at the Cenomanian-Turonian boundary: Geology, v. 29, p. 523-526.

Ripepe, M., and Fischer, A. G., 1991, Stratigraphic rhythms synthesized from orbital variations, in Franseen, E. K., Watney, W. L., Kendall, C. G. St. C., and Ross, W., editors, Sedimentary Modeling; Computer Simulations and Methods for Improved Parameter Definition: Kansas State Geological Survey, Bulletin 233, p. 335-344.

Sageman, B. B., Rich, J., Arthur, M. A., Birchfield, G. E., and Dean, W. E., 1997, Evidence for Milankovitch periodicities in Cenomanian-Turonian lithologic and geochemical cycles, Western Interior U.S.: Journal of Sedimentary Research, v. 67, p. 286-301.

Sageman, B. B., Meyers, S. R., and Arthur, M. A., 2006, Orbital time scale and new C-isotope record for Cenomanian-Turonian boundary stratotype: Geology, v. 34, p. 125-128.

Schiffelbein, P., and Dorman, L., 1986, Spectral effects of time-depth nonlinearities in deep sea sediment records: a demodulation technique for realigning time and depth scales: Journal of Geophysical Research, v. 91, p. 3821-3835.

Schlanger, S. O., Arthur, M. A., Jenkyns, H. C., and Scholle, P. A., 1987, The Cenomanian-Turonian Oceanic Anoxic Event, I. Stratigraphy and distribution of organic carbon-rich beds and the marine $\delta^{13} \mathrm{C}$ excursion, in Brooks, J., and Fleet, A. J., editors, Marine Petroleum Source Rocks: London, Geological Society, Special Publication, v. 26, p. 371-399.

Scholle, P. A., and Arthur, M. A., 1980, Carbon isotope fluctuations in Cretaceous pelagic limestones: potential stratigraphic and petroleum exploration tool: American Association of Petroleum Geologists Bulletin, v. 64, p. 67-87.

Schwarzacher, W., 1947, Uber die Sedimentare Rhythmik des Dachsteinkalkes vo Lofer: Geologische Bundesanstalt, Verhandlungen, v. H10-12, p.175-188.

Thomson, D. J., 1982, Spectrum estimation and harmonic analysis: IEEE Proceedings, v. 70, p. 1055-1096.

— 1990, Quadratic-inverse spectrum estimates: applications to palaeoclimatology: Philosophical Transactions of the Royal Society of London A, v. 332, p. 539-597.

Thomson, D. J., and Chave, A .D., 1991, Jackknifed error estimates for spectra, coherences and transfer functions, in Haykin, S., editor, Advances in Spectrum Analysis and Array Processing, Volume 1: Englewood Cliffs, New Jersey, Prentice-Hall, p. 58-113.

Tsikos, H., Jenkyns, H. C., Walsworth-Bell, B., Petrizzo, M. R., Forster, A., Kolonic, S., Erba, E., Premoli Silva, I., Baas, M., Wagner, T., and Sinninghe Damste, J. S., 2004, Carbon-isotope stratigraphy recorded by the Cenomanian-Turonian Oceanic Anoxic Event II: correlation and implications based on three key localities: London, Journal of the Geological Society, v. 161, p. 1-9. 
Watkins, D. K., 1989, Nannoplankton productivity fluctuations and rhythmically bedded pelagic carbonates of the Greenhorn Limestone (Upper Cretaceous): Palaeogeography, Palaeoclimatology, Palaeoecology, v. 74, p. 75-86.

Weedon, G., 1989, The detection and illustration of regular sedimentary cycles using Walsh power spectra and filtering, with examples from the Lias of Switzerland: London, Journal of the Geological Society, v. 146, p. 133-144.

Weedon, G. P., and Jenkyns, H. C., 1999, Cyclostratigraphy and the Early Jurassic timescale: data from the Belemnite Marls, Dorset, southern England: Geological Society of America, Bulletin, v. 111, p. 18231840 . 